Editorial

Volume 10 - $2020 \mid$ n. 37

\title{
REVISTA FINEDUCA - 10 ANOS DE CONTRIBUIÇÃO À PESQUISA EM FINANCIAMENTO DA EDUCAÇÃO
}

\author{
Ângelo Ricardo de Souza ${ }^{1}$ \\ José Marcelino de Rezende Pinto ${ }^{2}$ \\ Juca Gil ${ }^{3}$ \\ Márcia Aparecida Jacomini ${ }^{4}$ \\ Nalú Farenzena ${ }^{5}$
}

Em 1985, quando um dos autores deste editorial resolveu estudar financiamento da educação em seu mestrado, as referências sobre a temática cabiam nos dedos da mão. Em 2010, quando se decidiu criar a Revista Fineduca, após 22 anos da Constituição Federal de 1988, 10 anos de Fundo de Manutenção e Desenvolvimento do Ensino Fundamental e Valorização do Magistério (Fundef) e o Fundo de Manutenção e Desenvolvimento da Educação Básica e Valorização dos Profissionais da Educação (Fundeb) entrando em sua plenitude, a realidade já era outra. A política de fundos mostrou, como bem afirmou Nicholas Davies, que já era tempo de os pesquisadores da área educacional mergulharem com profundidade nas questões envolvendo os recursos destinados à educação, o impacto da política de fundos, as desigualdades, as formas de valorização dos profissionais da educação, as diferentes nuances dos mecanismos de privatização do ensino e o custo de uma escola de qualidade.

Já era hora de aglutinar em uma entidade os pesquisadores que debatiam os temas do financiamento em diferentes associações científicas, como a Associação Nacional de PósGraduação e Pesquisa em Educação (Anped) e a Associação Nacional de Política e Administração da Educação (Anpae), esta última, berço de fundação da Associação Nacional de Pesquisa em Financiamento da Educação (Fineduca), concebida em 28 de abril de 2011, no prédio da Pontifícia Universidade Católica de São Paulo (PUC/SP). E a nova associação já nasceu com o lançamento da Revista Fineduca, conforme consta em sua ata de fundação.

Em 2010, quando se decidiu criar o periódico, a ideia de uma revista acadêmica totalmente eletrônica era algo incomum à tradição da área da Educação no Brasil. A organização dos artigos em um único volume anual, com artigos publicados de forma contínua, individualmente, fora dos padrões usuais, como trimestral, quadrimestral ou semestral, era rara naquele momento. Parecia um tanto ousado, mas a Revista Fineduca iniciou sua trajetória sem temer inovações, em parte impulsionada pelas próprias condições objetivas para a criação de uma revista dedicada à

\footnotetext{
Professor da Universidade Federal do Paraná (UFPR).

Professor da Universidade de São Paulo - Ribeirão Preto (USP).

3 Professor da Universidade Federal do Rio Grande do Sul (UFRGS).

4 Professora da Universidade Federal de São Paulo (UNIFESP).

5 Professora da Universidade Federal do Rio Grande do Sul (UFRGS).
} 
temática do financiamento da educação, que, embora em crescimento, ainda era bem pequena se comparada a outras temáticas das pesquisas em/sobre educação. Havia também a motivação econômica, pois os custos eram muito menores na versão digital, e a entidade, desde o seu nascimento, tem vivido sob o regime da pobreza. A realidade mudou radicalmente e hoje raros são os periódicos que imprimem seus números, havendo ainda outros que o fazem de forma secundária, sendo as plataformas virtuais o principal modo de acesso e leitura.

Abrigar a revista numa plataforma usuária do Sistema Eletrônico de Editoração de Revistas (SEER), uma adaptação do Open Journal Systems (OJS), não foi uma dificuldade naquele momento, ao contrário, contribuiu para agilidade do processo editorial e demonstrouse muito funcional. Assim, por praticidade, a revista foi instalada junto à instituição do seu primeiro editor, na plataforma SEER da Universidade Federal do Rio Grande do Sul (UFRGS).

Além da eficiente e intuitiva operacionalidade, o SEER possibilitou iniciarmos a editoria sem o apoio de funcionários dedicados à secretaria, sendo terceirizadas a revisão e a diagramação.

Quem nasceu primeiro, a revista Fineduca ou a entidade Fineduca? De fato, ambas vieram ao mundo juntinhas, numa concepção de mútua complementaridade. A primeira chamada pública de artigos da revista ocorreu em 14/02/2011, sendo que a associação foi fundada oficialmente pouco mais de dois meses depois, em 26/04/2011. Assim, a entidade ainda nem havia sido registrada em cartório quando os primeiros artigos da revista foram publicados, dois dias após a fundação, em 28/04/2011.

Nesse período de 10 anos, tanto a Associação Nacional de Pesquisa em Financiamento da Educação (Fineduca), que tem realizado encontros anuais, quanto a revista, consolidaramse e constituem, de forma articulada, importante espaço de estudo, pesquisa, formação e debates sobre financiamento da educação.

Com Comitê e Conselho Editoriais formados por pesquisadores da área da Educação e, principalmente, do financiamento da educação, a revista teve, em seus 10 anos, cinco editores: Juca Gil (2011 a 2013), Ângelo Ricardo de Souza (2013 e 2014), José Marcelino de Rezende Pinto e Nalú Farenzena (2015 a 2019) e Márcia Aparecida Jacomini e José Marcelino de Rezende Pinto (setembro de 2019 até o momento).

A proposta inicial era publicar, ao menos, 12 artigos anuais, uma meta que encontrou fortes dificuldades para decolar, sendo que os últimos artigos do volume do ano inicial só foram publicados em 2013. Nesse mesmo ano também foi publicada a maioria dos artigos referentes ao volume 2, de 2012. A partir de 2014 obtivemos maior estabilidade e regularizamos o fluxo de publicações. As hipóteses para as dificuldades iniciais não estavam relacionadas a pouca produção sobre o financiamento da educação. Parece-nos que o problema residia tanto na pouca confiança num modelo editorial desconhecido (apenas digital e anual) quanto no fato de a revista não ter sido avaliada pela Coordenação de Aperfeiçoamento de Pessoal de Nível Superior (Capes) e, portanto, não possuir uma classificação no Sistema Brasileiro de Avaliação de Periódicos - Qualis/Periódicos/CAPES, à época então ainda pouco atrativa para os pesquisadores, especialmente os mais experientes.

Mas o fortalecimento institucional da entidade e seus encontros anuais, somados à disseminação do formato editorial por parte de diversos periódicos mais tradicionais, abriram espaço para o crescimento da revista. A regularização do fluxo de captação de artigos e o aprimoramento editorial levaram nosso periódico a ser credenciado junto a diversos 
indexadores, o que, no conjunto, possibilitou a obtenção do Qualis B2, na avaliação 2013-2016, e B1, na avaliação extraoficial realizada em 2019.

Ao longo desses 10 anos foram publicados 156 artigos. Entre 2011 e 2017 foram publicados 12 artigos por ano, com exceção de 2015, em que publicamos 14 artigos. Em 2018 foram 13 publicações, em 2019, 24, e 33 trabalhos em 2020. Em 2019 foi publicada a primeira seção temática da revista Carreira e Remuneração Docente, organizada pelos/as professores/as Marcos Edgar Bassi, Maria Dilméia Espíndola Fernandes e Rosana Maria Gemaque Rolim. A segunda seção temática da revista, Balanço do Fundeb, organizada pelos/as professores/as Márcia Aparecida Jacomini e José Marcelino de Rezende Pinto, foi publicada em 2020. Devido ao grande número de artigos recebidos e aprovados para essa seção temática, uma segunda parte será publicada no início de 2021. Além dos artigos, nesse período foram publicados: um texto em Clássicos e Históricos, um na Série Documentos, quatro editoriais, duas apresentações de seção temática, uma resenha de livro e um resumo de tese e dissertação.

Os artigos publicados na Revista Fineduca até o momento foram escritos por 310 autores, sendo que alguns desses escreveram mais de um artigo ao longo desse ciclo. No cômputo de autores, verificamos que, do ponto de vista geopolítico, o periódico abrangeu todas as regiões brasileiras, tendo representações de 21 unidades da federação, a saber: Acre, Amazonas, Bahia, Ceará, Distrito Federal, Espírito Santo, Goiás, Maranhão, Mato Grosso, Mato Grosso do Sul, Minas Gerais, Pará, Paraíba, Paraná, Piauí, Rio de Janeiro, Rio Grande do Norte, Rio Grande do Sul, Rondônia, Santa Catarina e São Paulo; além de três países: Argentina (Buenos Aires), Uruguai (Montevidéu), Chile (Santiago e Talca).

Se em termos nacionais nossa revista demonstra capilaridade em diferentes rincões, do ponto de vista da internacionalização temos enfrentado enormes dificuldades. Nesse primeiro decênio, contamos com 10 autores estrangeiros em apenas 6 artigos, oriundos de 4 cidades de 3 países: Argentina, Uruguai e Chile. Não obstante a concentração, cinco dos seis artigos advém de distintas instituições acadêmicas. É notória a necessidade de ampliarmos nossos horizontes de diálogos com outros países, continentes e idiomas, projeto que nos desafia para o próximo período.

De toda forma, a Revista Fineduca alcançou, com esta publicação diversa e ampliada, uma rede de leitores igualmente ampla, que se esparrama por todo o território nacional, mas que precisa ainda conquistar leitores no exterior, especialmente nos países da lbero-América. Durante esses 10 anos, a Revista atingiu 230 citações, e apresenta um $h$ index (Google Scholar) igual a 7 , o que a coloca em uma posição compatível a seu tempo de existência e à especificidade de seu objeto, em uma comunidade crescente de pesquisadores, mas que ainda é um tanto restrita.

Quanto às temáticas abordadas nas publicações, parece necessário envidarmos esforços para melhor delimitar palavras-chave e conceitos que nos permitam classificar os artigos de modo inteligível e multifacetado, evitando simplificações. Quais são as formas interessantes de agregar os temas? Como tratar temáticas fronteiriças entre abordagens diversas? Usar a abrangência político-geográfica como compilador? As etapas e as modalidades são boas referências? Dadas as dificuldades que neste momento configuram limites analíticos, podemos destacar três temáticas que sobressaem no período: financiamento da educação, envolvendo os dois níveis de educação, as diferentes etapas e modalidades de ensino e diversas subtemáticas (valendo citar, entre outras, a política de fundos o gasto/aluno), 
com 85 artigos; carreira, condições de trabalho e remuneração docente, que contabilizou 57 artigos; e privatização e parcerias público-privado na educação, com 14 artigos.

Uma análise mais detalhada das publicações da Revista Fineduca certamente trará informações importantes para os desafios que se apresentam: ampliar a inserção da revista de maneira a publicar artigos de autores de todos os estados e de outros países. Como veículo que tem contribuído também para a formação de novos pesquisadores, uma análise das perspectivas teórico-metodológicas utilizadas nos artigos que publicamos para identificar tendências e localizar lacunas será de grande importância para a consolidação das pesquisas no campo do financiamento da educação.

No intuito de provocar reflexões, colocamo-nos as seguintes perguntas: as pesquisas em financiamento da educação estão se apropriando de métodos quantitativos? Temos interfaces com os estudos realizados nos campos da administração e da economia? Estamos dialogando com a produção acadêmica de países anglófonos? $\mathrm{O}$ que poderíamos aprender com referenciais africanos ou asiáticos?

Do ponto de vista da organização editorial, entendemos que a criação da seção temática, em 2019, representou um salto com forte impacto tanto na profundidade de abordagem a uma questão específica quanto na ampliação da capacidade de captação de artigos, trazendo promissoras perspectivas de futuro.

Enfim, comemoramos o décimo aniversário da Revista Fineduca felizes com o fato de estarmos nos consolidando como uma referência atinente à produção acadêmica em financiamento da educação, constituindo um canal reconhecido para a disseminação de pesquisas acerca da temática.

Reafirmamos também nosso compromisso com a linha editorial em defesa de uma escola pública, laica, estatal, democrática e de qualidade para todos/as os/as brasileiros/as, conforme definido nos estatutos da entidade Fineduca.

Finalizamos este editorial com um agradecimento especial a todos/as que fazem a Revista Fineduca.

Aos pesquisadores/autores que têm enviado seus artigos, sem vocês a revista não existiria. Continuem prestigiando o periódico com os resultados de suas pesquisas/estudos.

Aos atuais membros do Comitê Editorial, pela importante contribuição na organização da revista: Nalú Farenzena, Juca Gil, Theresa Adrião e Ângelo Ricardo de Souza.

Aos nossos pareceristas ad hoc, um imenso agradecimento pelas avaliações cuidadosas e sugestões aos autores, que muito contribuem para publicarmos o máximo de artigos que recebemos. Os pareceres são sem dúvida importantes na formação dos jovens pesquisadores de financiamento da educação.

Queremos destacar algumas pessoas, cujo trabalho na revista tem sido imprescindível: Edson Leonel de Oliveira, responsável pela revisão dos textos e edição; Ananyr Fajardo (até 2019) e Sabrina Ferreira na revisão dos textos em inglês; Caroline Cristiano Cardoso, que, quando mestranda na UFRGS, ajudou-nos no processo de indexação da revista; Patrícia Balthazar Garcia e Caio Cabral da Silva, no apoio ao Comitê Editorial. Nossos sinceros agradecimentos, desejamos seguir trabalhando com vocês por muitos anos.

Vida longa à Revista Fineduca! 


\section{Editores do volume 10}

Márcia Aparecida Jacomini - Universidade Federal de São Paulo, Brasil

José Marcelino de Rezende Pinto - Universidade de São Paulo, Brasil

\section{Comitê Editorial}

Nalú Farenzena - Universidade Federal do Rio Grande do Sul, Brasil

Juca Gil - Universidade Federal do Rio Grande do Sul, Brasil

Theresa Adrião - Universidade Estadual de Campinas, Brasil

Ângelo Ricardo de Souza - Universidade Federal do Paraná, Brasil

\section{Conselho Editorial}

\section{Alejandro Morduchowicz}

Universidad Pedagógica, Provincia de Buenos Aires, Argentina

Andréa Barbosa Gouveia

Universidade Federal do Paraná, Brasil

Fernanda Saforcada

Universidade de Buenos Aires, Argentina

Jacques Velloso

Universidade de Brasília, Brasil

João Monlevade

Senado Federal, Brasil

Jorge Abrahão de Castro

Instituto de Pesquisa Econômica Aplicada / IPEA, Brasil

Lisete Regina Gomes Arelaro

Universidade de São Paulo, Brasil

Luis Carlos Sales

Universidade Federal do Piauí, Brasil

Luiz de Sousa Junior

Universidade Federal da Paraíba, Brasil

Luiz Fernandes Dourado

Universidade Federal de Goiás, Brasil

Magna França

Universidade Federal do Rio Grande do Norte, Brasil

Marcos Edgar Bassi

Universidade Federal de Santa Catarina, Brasil

Maria Angélica Pedra Minhoto

Universidade Federal de São Paulo, Brasil

Maria Beatriz Luce

Universidade Federal do Rio Grande do Sul, Brasil

Maria Dilnéia Espíndola Fernandes

Universidade Federal de Mato Grosso do Sul, Brasil

Nelson Cardoso do Amaral

Universidade Federal de Goiás, Brasil

Nicholas Davies

Universidade Federal Fluminense, Brasil

Robert E. Verhine

Universidade Federal da Bahia, Brasil

Romualdo Portela de Oliveira

Universidade de São Paulo, Brasil

Rosana Gemaque Rolim

Universidade Federal do Pará, Brasil

Rubens Barbosa de Camargo

Universidade de São Paulo, Brasil

Theresa Adrião

Universidade Estadual de Campinas, Brasil

Tristan McCowan

University of London, Reino Unido

Vera Jacob

Universidade Federal do Pará, Brasil

Vera Peroni

Universidade Federal do Rio Grande do Sul, Brasil

Vitor Henrique Paro

Universidade de São Paulo, Brasil

\section{Equipe editorial}

Apoio ao Comitê Editorial: Caio Cabral da Silva

Diagramação, Revisão de português e normalização: Edson Leonel de Oliveira

Revisão de inglês: Sabrina Ferreira

Fineduca - Revista de Financiamento da Educação

Associação Nacional de Pesquisa em

Financiamento da Educação

e-mail: revista.fineduca@gmail.com | site: http://seer.ufrgs.br/fineduca 